\title{
Assessing physical and environmental factors in a home appliance manufacturing facility
}

\author{
Berna H. Ulutas (bhaktan@ogu.edu.tr) \\ Department of Industrial Engineering, Eskisehir Osmangazi University \\ 26480 Eskisehir, Turkey
}

\begin{abstract}
It is known that worker's performance is related with several factors such as working postures and environmental factors. This study aims to attract attention to the importance of quantifying and assessing factors in a home appliance manufacturing facility. Twenty five assembly line workers are asked to assess environmental conditions and fill out Cornell discomfort survey based on the tasks they perform. Then, video records are analyzed to identify working postures by use of OWAS. Statistical analysis are made to identify whether the factors have a significant effect on the tasks performed or not.
\end{abstract}

Keywords: physical factors, environmental factors, OWAS

\section{Introduction}

With the increase of product variety and importance of assembly lines, the studies on repetitive movements and postural problems are also gaining importance. Many postural observational methods have been advocated in the literature to evaluate exposure to musculoskeletal disorder (MSD) risk factors associated with work. Since, MSD can cause work loss for the company and adversely affect worker's health, the problem is considered in this study

\section{Method}

There are several observational methods used to assess postural risks. Ovako working posture analysis system (OWAS) is a simple observational method for analyzing and controlling poor postures at a worksite. Conventional OWAS is based on sampling from typical working postures for the whole body, which covers the most common and easily identifiable working postures for the trunk, arms, and legs, along with an estimate of the worker's force. Related tables available at http://www.hse.gov.uk/research/hsl_pdf/2002/hs102-31.pdf are utilized. To confirm the results, Quick Exposure Check (QEC) that aims to be a user friendly practical tool for the assessment of physical exposure to risks for work-related musculoskeletal disorders ( $\mathrm{Li}$ and Buckle, 1999) is also used. Rapid Body Assessment (REBA) developed as a postural analysis tool to be sensitive to the type of unpredictable working postures found in health care and other service industries (Hignett and McAtamney, 2000).

A survey is designed to obtain data from assembly line workers related to factors such as, environmental, physical, chemical, and biomechanical risks (Appendix). Further, workers are asked to reply Cornell Musculaskelatal Discomfort Questionnaire (CMDQ) available at http://ergo.human.cornell.edu/ahmsquest. html based on the number of symptoms they face.

\section{Results}

The observations in the study are made in a fully private capital company that is one of the European market leaders in large household appliances: washing machines, dishwashers, dryers, refrigerators, freezers, cookers and ovens, for built-in and free standing. It delivers through two international brands and national brands such as. The company has 8 production sites in Europe and China, 39 the subsidiaries in the world. The factory in Eskisehir started production in 2007. With its 750 employees now producing cooking appliances to the group's worldwide brands.

\subsection{Assembly line in concern}

The study is conducted in the dryer assembly line of the aforementioned factory with 25 workstations. Figure 1 represents the layout of the facility and the line. 


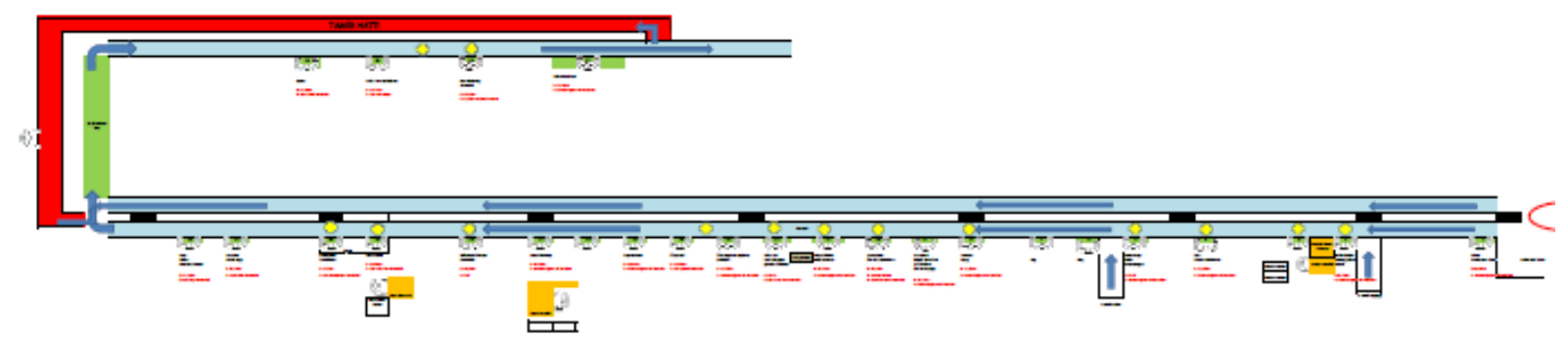

Figure 1. The assembly line layout in concern

\subsection{Assessment survey}

In the first step of the study, workers are asked to assess environmental conditions in terms of climate, noise, and illumination. Based on the ten scale answers, it is figured out that only the temperature of the working areas are felt higher even in the winter season. On the other hand there was no significant complaints related with noise and illumination.

Figure 2 represents the CMDQ results and points out the severity of the pain that is felt by the workers. It can be stated that the neck and back pain are the high risk areas.

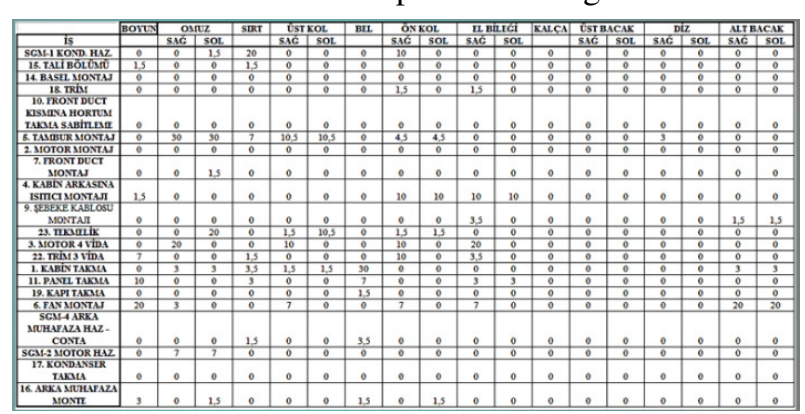

Figure 2. CMDQ results

\subsection{Comparison of the results}

The posture of a worker that allows the harmfulness of the posture to be categorised into four Action Categories of increasing urgency. It is based upon expert judgements of the harmfulness of particular postures. A time-based sampling approach can be used with it so that the categorisation is utilized as suggested to take account of the length of time spent in any particular posture (Karhu et al., 1977, 1981, Kivi and Mattila, 1991, Vedder, 1998)

Figure 3 represents OWAS module in ErgoFellow Program. Since The assembly parts are lower than $10 \mathrm{~kg}$, the assessments results calculated as 2 . Therefore, other related methods are used to assess the workstations. Results generated are summarized in Table 1.

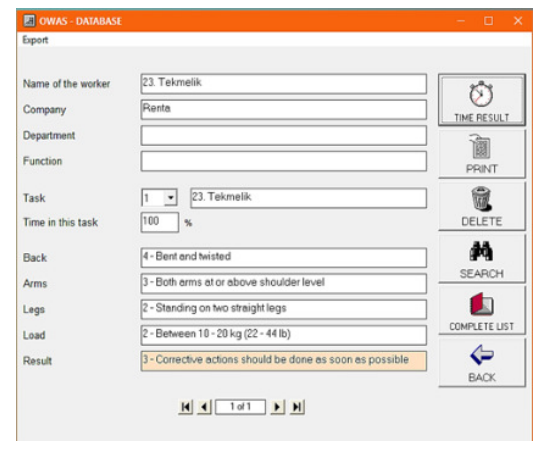

Figure 3. OWAS module in ErgoFellow

Table 1. Results for the assessment

\begin{tabular}{|c|c|c|c|}
\hline Work Station & QEC (\%) & REBA & OWAS \\
\hline 5 & 0,81 & 12 & 2 \\
\hline 16 & 0,83 & 11 & 2 \\
\hline 23 & 0,77 & 10 & 2 \\
\hline 19 & 0,75 & 8 & 2 \\
\hline 11 & 0,75 & 8 & 2 \\
\hline 1 & 0,75 & 8 & 2 \\
\hline 22 & 0,83 & 8 & 2 \\
\hline 3 & 0,79 & 7 & 2 \\
\hline 2 & 0,70 & 7 & 2 \\
\hline 7 & 0,70 & 7 & 2 \\
\hline 24 & 0,73 & 7 & 2 \\
\hline 6 & 0,68 & 7 & 2 \\
\hline 17 & 0,70 & 6 & 2 \\
\hline 8 & 0,74 & 5 & 2 \\
\hline 25 & 0,67 & 5 & 2 \\
\hline 21 & 0,63 & 4 & 2 \\
\hline 12 & 0,63 & 3 & 2 \\
\hline 14 & 0,71 & 6 & 2 \\
\hline 15 & 0,68 & 5 & 2 \\
\hline 18 & 0,67 & 5 & 2 \\
\hline 10 & 0,72 & 6 & 2 \\
\hline 4 & 0,69 & 5 & 2 \\
\hline 9 & 0,72 & 6 & 2 \\
\hline
\end{tabular}



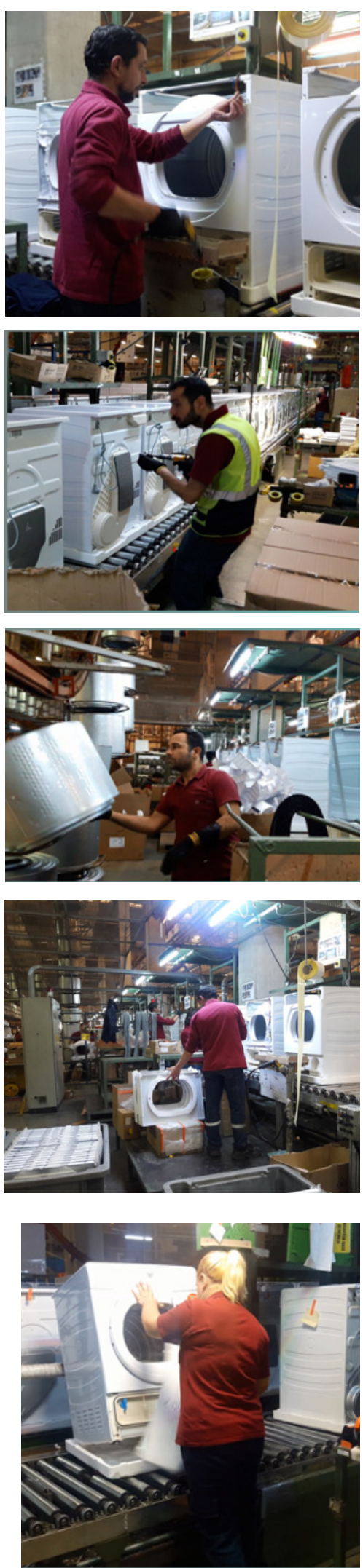

Figure 4.Photos from the problematic work stations

\section{Conclusion}

Environmental, physical, and biomechanical factors should be assessed in every assembly line periodically to keep the workers healthy and sustain the operations. However, as this study tries to attract attention, depending on a single methodology can be misleading. Therefore, it is required to consider worker's complaints first and then use supporting methods to avoid relying on one methodology only. Similar surveys and methods have potential to be used in other assembly lines in future studies.

\section{Acknowledgements}

The author would like to thank undergraduate student Ms. Aysenur Turker for the support during data gathering and Mr. Mustafa Can Tuncer for providing the opportunity to assess the manufacturing line.

\section{References}

http://www.hse.gov.uk/research/hsl_pdf/2002/hs102-31.pdf (retrieved on May 2017)

http://ergo.human.cornell.edu/ahmsquest.html (retrieved on May 2017)

http://www.fbfsistemas.com/ergonomics.html (retrieved on May 2017)

Karhu,O., Kansi,P. and Kuorinka,I. (1977), "Correcting working postures in industry: Apractical method for analysis", Applied Ergonomics, 8, (4), 199-201.

Kivi,P. and Mattila,M. (1991), "Analysis and improvement of work postures in the buildingindustry: Application of the computerised OWAS method", Applied Ergonomics, 22, (1), 43-48

Vedder,J. (1998), "Identifying postural hazards with a video-based occurrence sampling method", International Journal of Industrial Ergonomics, 22, (4-5), 373-380 
Appendix
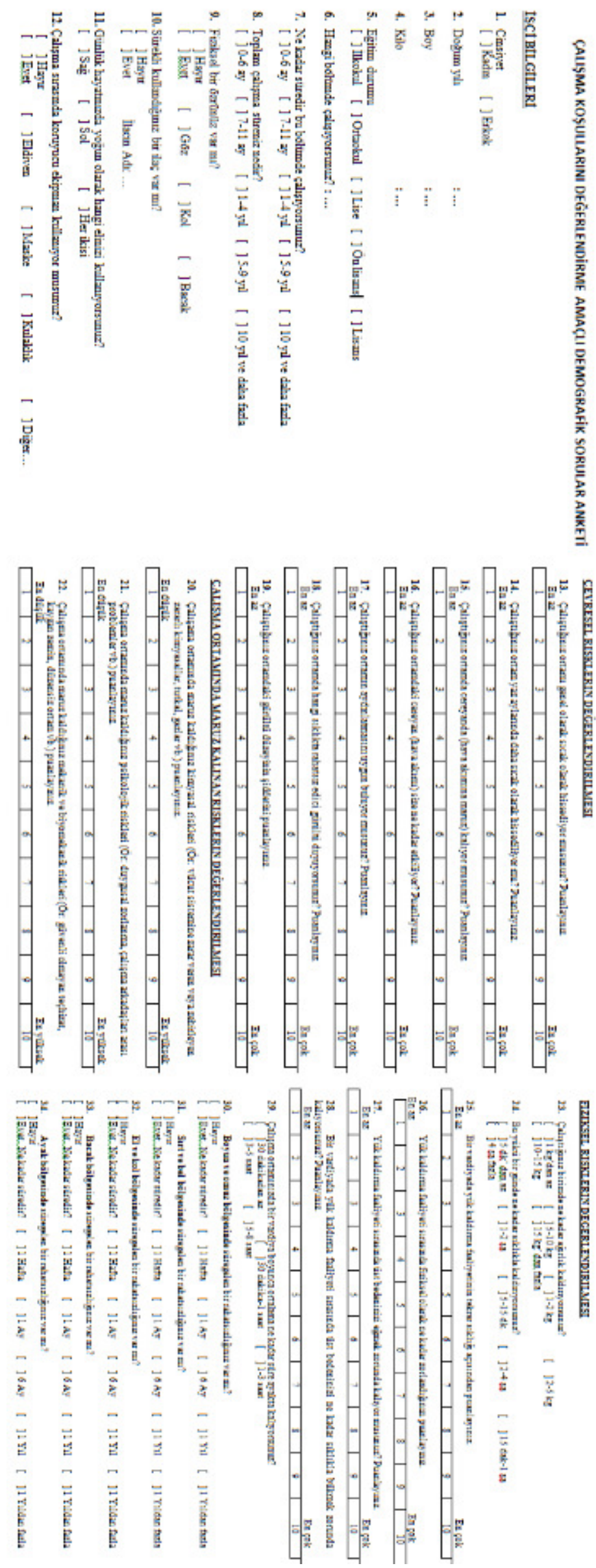